E3S Web of Conferences 2, 02004 (2014)

DOI: $10.1051 /$ e3sconf/ 20140202004

(C) Owned by the authors, published by EDP Sciences, 2014

\title{
Economics and science in higher education: the need for a common language
}

\author{
Francesco Gonella \\ Dept. of Molecular Sciences and Nanosystems, Università Ca' Foscari Venezia, Dorsoduro 2137, \\ 30123 Venice, Italy
}

\begin{abstract}
Science literacy is strongly needed in all fields inspired by the concept of Sustainable Development. The need for integrated courses is addressed for science, engineering and economics master students, focused on the systemic approach.
\end{abstract}

\section{What's new}

Scientific illiteracy presents several aspects. The modern science, for describing which a high level of cultural background is required, is in some sense unavoidably unknown to the most. Other aspects have to do with the misunderstanding in the comprehension of some basic scientific concepts, among which Darwin's Evolution Theory is probably the most relevant example. But what is becoming more and more important is that science has been producing something else, besides the technological advancements that are often identified as "the" science, and that science may provide as well suitable conceptual tools for a better understanding of the reality, tools that we all would like to be possessed by those who rule the society, both at a local and at a global level. In this sense, it is somewhat interesting to remark how mass media do not seem to make any real effort to provide comprehensible lowdowns of what is really happening, or to fight both science and ecomonics illiteracy whatsoever.

The starting point of what I am going to talk about comes from a simple consideration: most of the basic issues that characterize modern societies as they have been transformed in the last two decades are based on systems (social, economical, technological, political) which exhibit behaviors typical of Complex Systems [1]. Systems whose behavior is not predictable from the simple knowledge of how their components work, systems that exhibit unexpected emergent properties as a whole, systems that embed a network of feedbacks between their subsystems, and systems whose general behavior is all but linear, depending critically on the values of internal variables and/or external parameters whose fluctuation may induce even cahotic or catastrophic behaviors. Terms like emergence, linearity, criticality, cahotic, catastrophic, and so on find a specific role in System Theory, but at the same time are used within other contexts -including the everyday life language- with different meanings, so giving a peculiarly interesting contribution to the scientific functional illiteracy.

Several local and global problems, such as -paradigmatically- the "energy problem", should be faced with skills, tools, languages, approches and methodologies that are own of complex systems science. Scientific illiteracy is in this sense a crucial aspect, as long as policy makers have to face social and environmental problems that require technical tools belonging to interdisciplinary scientific realms. If, as David Goodstein observes, "Approximately 95 percent of the [American] public is illiterate in science by any rational definition of science literacy" [2], there is a little hope that policy makers are all taken from the remaining $5 \%$, whereas science literacy is needed in all decision-making 
processes dealing with complex technology-based and environmental systems, and in general with all the actions inspired by the concept of Sustainable Development.

Of course, this is not a new point. Since the 70s, scholars from different scientific disciplines have developed the awareness that several phenomena in different contexts exhibit the same physicomathematical description. Features -and therefore concepts- like self-organization, criticality, emergent properties are currently applied in several different fields, by means of proper isomorphisms of the respective involved variables. But nowadays, as a matter of fact, Economists seems to have taken the burden of the analysis of the social systems as well as that of providing local and global solutions, at the same time demonstrating their actual inability to do the job. The political and economical reasons for this lie far beyond the scope of this contribution, maybe forming themselves a complex system, and it is clear that science alone is somewhat marginal in this context. But, as far as some "scientific thinking" has entered the non-scientific disciplines, among which is Economics, it appears necessary that a potentially useful modern scientific knowledge becomes part of the current higher education curricula even outside the Science courses. What I claim here is then the strong need for a cultural transmission of knowledge from Science to Economics that starts in the University curricula. People who are called to take public decisions, be them economists, politicians, policy makers of some kind, or even scientists, gain their competences and skills on global problems only after they got their University degree in their respective disciplines. Quite often, only at the PhD level the Academy provides trans- and multi-disciplinary approaches for specific fields of study. But, as far as either "interdisciplinary" or "multidisciplinary" become actual descriptors of research subjects, the problem of finding a common language for managing the topic at issue has become in turn an actual bottleneck for the development of effective approaches. In this sense, the very concept of "sustainability" is probably the best one to represent this need, forcing researchers to adopt a systemic approach in its widest sense.

Both interdisciplinarity and complexity are actually strictly linked in a wide range of practices, since any of the two concepts very often comes into play whenever the other one is a peculiar keyword in an analysis. As long as a system exhibits different levels of organization in space or in time, its very description will include corresponding different levels of language and analytical tools, that sometimes will result just ineffective if a classical, reductionist approach is used. This happens in particular whenever the evolution of the system at issue involves the emergence of properties that shift our capability of describing (and therefore foreseeing) toward different immeasurable sets of concepts.

In the updating process of their educational curricula, academic Institutions tend to react much faster to the specific novelties within the respective disciplines rather than to emergence of interand cross-disciplinary knowledge like that one represented by the Systems Theory. The main reasons for this are the very structure of the University courses, the University recruitment systems, the preparation of the professors themselves, often limited to a single discipline if not to a single subdiscipline, and the general inertia of the educational apparatuses to update their contents and their working methodologies. Quite often, only disciplines that are "transversal" by definition, like Environmental Sciences, cross the boundaries and propose, even within first and second degree curricula, modern scientific topics that come from traditionally separated disciplines. Especially for the most traditional, efforts are left to singles, or to educational projects that anyway are set only with great difficulty within the traditional curricula. But the development of transdisciplinary knowledge occurred in the last decades, significantly within the Physical Sciences, has put the basis for new interconnections among historically separated academic fields.

\section{The energy problem}

The so called "energy problem" is probably the most evident example of the necessity of an updated systemic approach [3,4]. Geo-political and environmental implications are strictly connected with the economical aspects of energy supply and distribution, as well as to the development of effective technologies able to guarantee a manageable substitution of the traditional energy sources with renewable ones. Answers to the energy problem were historically given depending on the decision 
makers or political lobbies that in turn have had the opportunity to operate. But the fact is that impoverishment of fossil fuels, geo-political instability, global warming and globalization (of markets) strongly push towards the establishment of a common language baseline, which may permit all these different aspects of the problem to be put together in the same analysis. Even though specific educational programmes related to the energy issue have been proposed in multi-national projects (see www.iee-library.eu), energy is treated very differently within the single curricula. As already observed above, different study approaches tend to use different meaning for the same concept, insofar reflecting traditional immeasurable lexicons. Energy in particular is the concept whose meaning is more often adapted to the different role it takes depending on the (sub)discipline it is used within. Physicists distinguish various forms of energy, as for example kinetics, thermal, nuclear, etc., whereas its use drives the definition of "different energies" in the description of the "energy systems": primary (solar, geothermal, planetary, fuels), secondary (at conversion stations), final (electricity, gasoline at user), useful (converted energy at user), and rejected (in the environment). This classification is remarkably interesting, since it shifts the attention toward the processes rather than the forms.

We all know that there are different forms of energy, and that some of them are "better" than the other ones. The existence of some sort of "quality index" in the energy computation comes directly from the first two principles of Thermodynamics in the form they are commonly known by nonspecialists: energy is conserved (1st principle) but part of it is irreversibly lost when doing something (2nd principle). Of course, the contradiction is only apparent, for what is "irreversibly lost" is not the energy, but our capability to exploit it (i.e., to do work), that depends on the energy form and so defines some quality scale of the forms. In this sense, it is worth noting that most of the times mass media use the term "energy", they actually intend (without of course any awareness of this) "exergy" [5], i.e., that part of energy that is convertible into useful work, thus representing the quality index of a certain form of energy.

Energy is an abstract concept, a mathematical quantity, and it can be numerically quantified. Since energy is not material, and is related only to the quantification of our capability of doing something, we actually do not produce energy, nor we sell, purchase, exchange, destroy or waste it. For instance, Italy does not "buy electrical energy from France", it just buys the right to plug-in, inside the French territory, to the local electric network (by the way, being the current in the HV lines of alternate type, literally nothing of material goes from France to Italy). What Frenchs do is actually to make something that makes some Italian working plans available. This was just an example, to point out how easily a commonly used concept may be thought of from quite different prospects. As a matter of fact, energy systems planning, at all spatial and temporal scales, has been carried on from biased frameworks, related in turn to technology, science, economy, geographical constraints, political situations, environment, et coetera. All of these aspects are strictly connected one each other in an inestricable network of feedbacks, including the fact that the very objective of the planning might not be that of having -for example- clean and unexpensive energy for all, but that of making richer a group of already rich people.

The need for a common language therefore comes from the need of putting together all the aspects related to how a system works. A common language requires a common baseline for the quantities involved in the study of the system at issue. In the case of environmental or socio-economical systems where energy plays a fundamental role, the quantity able to link quantitatively the four actual flows that drive the systems (matter, energy, information and money) actually exists, that is emergy. Emergy (from EMbodied enERGY), was defined by Howard T. Odum as "the available energy of one kind that is used up in transformations directly and indirectly to make a product or service" [6], so quantifying how much energy has been used to "create" something, that is, how much energy is embedded in a product or service (the "memory" of its building up). The unit of emergy is from a physical point of view the same of energy, but is called emjoule (eJ), telling us the available energy of one kind consumed in transformations. Without entering any detail about the emergy algebra, diagramming, accounting and analysis, it is here sufficient to know that emergy allows to analytically compare energy forms as well as energy sources and services, by expressing them in a common 
baseline, and by computing the emjoules required to produce the respective contributions to an energy system or network, as well as to any energy-related human activity.

In order to take the emergy concept outside the realm of traditional science, a new set of concepts has been defined, among which a peculiar importance is assumed by the emergy per money unit, that is, the emergy related to the generation of one unit of economic product (in currency), allowing one to convert (even somewhat not univocally) money transfers into emergy units, so pointing out the role played in energy flow processes by money transfers [7].

Systems emergy analysis starts from the definition of diagrams including all inputs and outputs carrying emergy flows, and suitable to establish a quantitative analysis accounting for all the interconnections within the system boundary and with the external environment. Performance indices like the following ones allow to make the analysis quantitatively prescriptive, to the extent it correctly accounts for the various interconnections and perform the correct units transformation.

- Emergy Yield Ratio = Total emergy used per unit of emergy invested. This is a measure of how much an investment allows a process to use local resources.

- Environmental Loading Ratio = Nonrenewable and imported emergy over renewable emergy. This is very similar in its effectiveness to indices used for evaluating an ecosystem stress.

- Emergy Sustainability Index = The ratio of the two indices above, giving a measure of how much a resource or process contributes to the economy per unit of environmental loading.

Emergy accounting gives a quantitative analysis of flows, allowing to evaluate and compare the global environmental sustainability of the various energy sources, and quantitatively estimating the resources and the services that cannot be estimated directly by an economic approach, for example, the biodiversity [8]. What I would like to underline here is that this is a potentially important example showing that a knowledge explicitly aimed at connecting scientific (physical) and economic quantities does exist. By the way, this kind of approaches are potentially more effective than the so-called "econophysics", which puts the basis of economic analysis using the laws of Thermodynamics by the establishment of suitable isomorphisms. The problem is that new knowledge remains unknown to the most as long as it remains out of any traditional curriculum in the University didactics.

\section{Two Myths, one prescription}

In conclusion, I would like to outline two myths and one prescription related to the teaching of Science and Economics in the Universities.

First Myth: Physics, like in general any of the so called "hard sciences", has to do only with either theories or applications. This idea depicts Physics as something producing abstruse theories, like the string theory and the standard model with inside the Higgs boson, or applications whose natural output is (properly patented) some piece of technology. Of course Physics has both these kinds of products (the latter being anyway a by-product much more than what people think), but it also has been producing, ever since its establishment, new languages, new concepts, new ways of thinking, as well as new operational tools for the study of systems, then including social and economical ones.

Second Myth: Economics is an intrinsically interdisciplinary field of knowledge, and may be taught and learned without a scientific background. Usually, Economics students are taught some financial mathematics and statistics, sometimes at a remarkably high level, but the idea that certain mathematics, first established for describing natural phenomena, can shed light on the core mechanisms of some economic systems, is still far from becoming a common pratice.

Of course, all this has to do with the idea that some sort of "universal culture" should be recovered, properly adapted to the demands of the modern societies and to the global problems we are facing, and that the University should be the place where some wisdom -if not transmitted- should be anyway pointed out as a possible (just one of the possible) goal. Less ambitiously, let me outline something that could be done for now, to be included in a slow but unavoidable renovation of the didactic programmes. The following items are then proposed to be delivered -as the content of a specific course- within the curricula of students of any scientific discipline, as well as those of economical and social sciences: 
- First and second laws of Thermodynamics

- Principles of System Theory

- Introduction to Complex Systems

- Self-organization and Emergent Properties

- Phase changes and criticality

- Chaos laws

- Entropy and emergy

- Flows analysis.

As David W. Orr [9] pointed out, "To teach economics without reference to the laws of thermodynamics or those of ecology is to teach a fundamentally important ecological lesson: that physics and ecology have nothing to do with the economy. That just happens to be dead wrong".

\section{References}

[1] L. Von Bertalanffy, General System Theory; Foundatuons, development, Applications (G. Braziller, New York, 1969).

[2] D. Goodstein, J. Sci. Edu. Technol. 1, 149 (1992).

[3] F. Gonella, S. Spagnolo, Proc. of the 5th Int. Conf. of Education, Research and Innovation (IATED Publ., 2012, ISBN: 978-84-616-0763-1).

[4] A. Hobson, Phys. Education 38, 109 (2003).

[5] G. Wall, Energy 13, 197 (1988).

[6] H.T. Odum, Environment, Power and Society (Wiley, New York, 1971).

[7] H.T. Odum, Environmental Accounting: Emergy and Environmental Policy Making (Wiley, New York, 1996).

[8] M.T. Brow, S. Ulgiati, J. Cleaner Prod. 10, 321 (2002).

[9] D.W. Orr, Ecological Literacy: Education and the Transition to a Postmodern World (New York State University Press, New York, 1992). 